\title{
Interlocução entre o procedimento de tradução de Boaventura de Sousa Santos e os preceitos de letramento informacional em saúde
}

\author{
Interlocution between the translation procedure of Boaventura de Sousa Santos \\ and the precepts of health literacy
}

\section{Interlocución entre el procedimiento de traducción de Boaventura de Sousa Santos y los preceptos de alfabetizácion informacional de la salud}

\author{
Juliana Moreira Pinto ${ }^{1}$ \\ Ligia Maria Moreira Dumont ${ }^{2}$
}

\begin{abstract}
Resumo
Possui como objetivo, demonstrar como os fundamentos teóricos do procedimento de tradução, propostos por Boaventura de Sousa Santos, podem contribuir para a área de Ciência da Informação, tendo como ambiente empírico a promoção do letramento informacional em saúde, através da interlocução entre os profissionais envolvidos com atendimento clínico e os pacientes. Avalia-se o procedimento da tradução, visando a possibilidade de aplicação às práticas de mediação da informação, por permitir a apropriação de informações que satisfaça plena ou parcialmente a troca de saberes entre atores com diferentes conhecimentos, ou de estratos sociais distintos. Tendo em vista que os indivíduos fazem parte de um contexto social, agindo sobre e sofrendo interferências deste espaço, a tradução pode auxiliar no desenvolvimento das práticas informacionais que se articulam em comunidades voltadas para a promoção do letramento informacional dos atores sociais, de diferentes naturezas éticas, educacionais, religiosas, políticas e profissionais. Isso promove o empoderamento dos cidadãos para exercerem a sua cidadania, o autoconhecimento e melhor convivência na sociedade.
\end{abstract}

Palavras-chave: Letramento informacional. Letramento informacional em saúde. Boaventura de Sousa Santos. Tradução.

\begin{abstract}
It aims to demonstrate how the theoretical foundations of the translation procedure, proposed by Boaventura de Sousa Santos, can contribute to the area of Information Science, having as an empirical environment the promotion of health literacy, through the interlocution between the professionals involved with clinical care and patients. The translation procedure is evaluated, aiming at the possibility of applying to information mediation practices, because it allows the appropriation of information that fully or partially satisfies the exchange of knowledge between actors with different knowledge or different social strata. Considering that individuals are part of a social context, acting on and interfering with this space, the translation can help in the development of informational practices that are articulated in communities aimed at promoting the informational literacy of social actors of different ethical natures, educational, religious, political and professional. This promotes the empowerment of citizens to exercise their citizenship, self-knowledge and better coexistence in society.
\end{abstract}

Keywords: Information literacy. Health literacy. Boaventura de Sousa Santos. Translation.

\footnotetext{
${ }^{1}$ Doutoranda em Ciência da Informação pela Universidade Federal de Minas Gerais. Belo Horizonte, MG. email: juliemor@uol.com.br

${ }^{2}$ Doutora em Ciência da Informação pela Universidade Federal do Rio de Janeiro, convênio com o IBICT. Professora Titular da Escola de Ciência da Informação da Universidade Federal de Minas Gerais, Belo Horizonte. e-mail: dumont@eci.ufmg.br
}

Comun. \& Inf., Goiânia, GO, v. 21, n. 3, p. 56-74, out./dez. 2018. 


\section{Resumen}

El objetivo de este trabajo es demostrar cómo los fundamentos teóricos del procedimiento de traducción, propuestos por Boaventura de Sousa Santos, pueden contribuir al área de Ciencia de la Información, teniendo como ambiente empírico la promoción del alfabetizácion informacional en salud, a través de la interlocución entre los profesionales involucrados con atención clínica y los pacientes. Se evalúa el procedimiento de la traducción, visando la posibilidad de aplicación a las prácticas de mediación de la información, por permitir la apropiación de informaciones que satisfaga plena o parcialmente el intercambio de saberes entre actores con diferentes conocimientos, o de estratos sociales distintos. Dado que los individuos forman parte de un contexto social, actuando sobre y sufriendo interferencias de este espacio, la traducción puede auxiliar en el desarrollo de las prácticas informacionales que se articulan en comunidades orientadas hacia la promoción del alfabetizácion informacional de los actores sociales, de diferentes naturalezas éticas, educativas, religiosas, políticas y profesionales. Esto promueve el empoderamiento de los ciudadanos para ejercer su ciudadanía, el autoconocimiento y la mejor convivencia en la sociedad.

Palabras clave: Alfabetización informacional. Alfabetización informacional en salud. Boaventura de Sousa Santos. Traducción.

\section{INTRODUÇÃO}

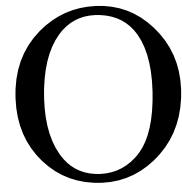

letramento informacional de pacientes da área de saúde tem recebido uma atenção crescente, tanto por parte de seus pesquisadores como das agências governamentais, devido não só ao bem estar das pessoas, mas à causa direta com os resultados de baixa adesão aos tratamentos, gerando aumento das hospitalizações, agravamento das doenças e elevação dos custos com a saúde. Superar essas barreiras, exige do profissional da saúde não somente conhecer as habilidades de leitura dos pacientes, mas utilizar recursos de informação para transpor as informações médicas a esse nível de habilidades (GAL; PRIGAT, 2005; BUCK, 1998). O letramento informacional é tema de pesquisa das autoras ${ }^{3}$, aliado à interlocução entre os profissionais envolvidos com os cuidados da saúde e os pacientes, com vistas à promoção do letramento informacional em saúde dos indivíduos.

Um trabalho inédito foi realizado pelos profissionais da saúde no Hospital Universitário de Brasília (HUB/UnB), para facilitar o entendimento sobre a utilização dos medicamentos e garantir a eficácia e segurança do tratamento dos pacientes do ambulatório de cardiologia do HUB. Foram traduzidas, isto é, reescritas e organizadas para uma linguagem simples, didática e de fácil entendimento para os pacientes, as bulas de medicamentos mais usados para tratamento das doenças cardíacas. No trabalho de tradução das bulas, os profissionais da saúde deram voz aos pacientes, que foram consultados antes e depois da elaboração dos textos para garantir a compreensão das informações repassadas sobre os medicamentos. Os pacientes tornaram-se colaboradores no processo de confecção

$3 \mathrm{O}$ artigo advém de uma pesquisa de doutorado.

Comun. \& Inf., Goiânia, GO, v. 21, n. 3, p. 56-74, out./dez. 2018. 
das bulas, mostrando sua visão de mundo, sua linguagem e seus interesses, somados às experiências dos profissionais da saúde sobre as doenças e medicamentos.

No trabalho intitulado "Para uma sociologia das ausências e das emergências", Boaventura de Sousa Santos (2002) teoriza sobre o trabalho de tradução, definido por ele como um procedimento de interpretação entre duas ou mais linguagens, cuja finalidade passa a ser identificar questões comuns entre elas, as diferentes respostas que lhe são dadas, transformando-se em um operador que busca a conexão, a compreensão entre culturas e conhecimentos distintos, permitindo que se encontrem seus elementos comuns.

Mediante o exposto e com a intenção de agregar as ideias de Boaventura de Sousa Santos aos constructos do letramento informacional, o objetivo geral do artigo é demonstrar como os fundamentos teóricos do trabalho de tradução propostos pelo autor, podem contribuir para a promoção do letramento informacional em saúde dos indivíduos. Espera-se com essa pesquisa contribuir para o avanço dos estudos sobre letramento informacional da área de Ciência da Informação, tendo como particularidade o letramento da área de saúde, bem como com as políticas públicas de proteção social voltadas para a educação e a saúde.

\section{A TRADUÇÃO PARA BOAVENTURA DE SOUSA SANTOS}

A tradução é o procedimento que permite criar inteligibilidade recíproca entre as experiências do mundo, tanto as disponíveis como as possíveis, reveladas pela sociologia das ausências $^{4}$ e a sociologia das emergências ${ }^{5}$ (SANTOS, 2002, p. 30-31). "A tradução é, simultaneamente, um trabalho intelectual e um trabalho político. Também é um trabalho emocional, porque pressupõe o inconformismo perante uma carência decorrente do caráter incompleto ou deficiente de um dado conhecimento ou uma dada prática" (SANTOS, 2002, p. 37).

Para que se possa compreender o trabalho de tradução, deve-se partir das seguintes indagações, propostas por Santos (2002, p. 38): O que traduzir? Entre o que traduzir? Quem

\footnotetext{
4 Uma investigação que visa demonstrar que o que não existe é, na verdade, ativamente produzido como não existente, isto é, como alternativa não credível ao que existe. O seu objeto empírico é considerado impossível à luz das ciências sociais convencionais, pelo que a simples formulação representa já uma ruptura com elas. O objetivo da sociologia das ausências é transformar objetos impossíveis em possíveis e com base neles transformar as ausências em presenças (SANTOS, 2002).

5 A sociologia das emergências consiste em substituir o vazio do futuro segundo o tempo linear (um vazio que tanto é tudo como é nada) por um futuro de possibilidades plurais e concretas, simultaneamente utópicas e realistas, que vão construindo no presente. O Ainda-Não é o modo como o futuro se inscreve no presente e o dilata. Não é um futuro indeterminado nem infinito. É uma possibilidade e uma capacidade concretas que nem existem no vácuo, nem estão completamente determinadas (SANTOS, 2002).
} 
traduz? Quando traduzir? Como traduzir?

A resposta à primeira pergunta (“O que traduzir?”) é dada pelo conceito de zonas de contato que, segundo Santos (2002, p. 38), "são campos sociais onde diferentes mundos da vida normativos, práticas e conhecimentos se encontram, chocam e interagem”. Para o autor, a zona de contato requerida pela razão cosmopolita é constituída por aquilo que cada saber ou prática decide que deve ser posto em contato e com quem deve contatar, a fim de que se identifique o que há de comum ou para ser aprendido entre eles.

À segunda pergunta (“Entre o que traduzir?”), pode-se responder que "a seleção dos saberes e práticas entre os quais se realiza o trabalho de tradução é sempre resultado de uma convergência ou conjugação de sensações ou experiências de carência, de inconformismo, e da motivação para superá-las de forma específica" (SANTOS, 2002, p. 40).

Em resposta à terceira interrogativa (“Quem traduz?”), pode-se afirmar, de acordo com Santos (2002, p. 42), que tal tarefa deve ser empreendida pelos intelectuais que possuem uma compreensão profunda e crítica a respeito de cada prática e saber envolvidos no processo de tradução e que desejam buscar em outros saberes/práticas, respostas que não se encontram dentro dos limites de seus saberes/práticas "de origem".

“Quando traduzir?” A essa pergunta, Santos (2002, p. 41) responde afirmando que "a zona de contato cosmopolita tem de ser o resultado de uma conjugação de tempos, ritmos e oportunidades. Sem tal conjugação, a zona de contato torna-se imperial e o trabalho de tradução torna-se uma forma de canibalização".

Quanto à quinta e última pergunta (“Como traduzir?”), Santos (2002, p. 42) explica que "o trabalho de tradução é, basicamente, um trabalho argumentativo, assente na emoção cosmopolita de partilhar o mundo com quem não partilha o nosso saber ou a nossa experiência".

Boaventura de Sousa Santos (2002) também explica que o trabalho de tradução pode ocorrer entre práticas, saberes e experiências. A tradução entre saberes ocorre por meio da hermenêutica diatópica, procedimento hermenêutico viabilizador do diálogo entre diferentes culturas, permitindo a identificação de preocupações semelhantes entre elas e as diferentes respostas que lhes são dadas. A hermenêutica diatópica é possível quando é identificada a noção de falta; a incompletude de todas as culturas é reconhecida e acredita-se na possibilidade de uma nova aprendizagem a partir do encontro e diálogo entre as mesmas. Saldanha (2007, p. 414), salienta que "o objetivo da hermenêutica diatópica não é atingir a completude, mas ampliar a sua consciência de incompletude por intermédio de um diálogo".

Ressalta-se, no entanto, as dificuldades ínsitas ao trabalho de tradução, decorrentes do 
fato de que toda argumentação é orientada por postulados, axiomas e ideias que não são objeto de discussão. Elas são aceitas como evidentes pelas pessoas que participam de um determinado círculo argumentativo $\left(\right.$ topo $\left.^{6}\right)$, ao passo que o trabalho de tradução não dispõe de um topoi, pois os disponíveis são próprios de determinados saberes ou práticas. Assim, faz-se necessário que na medida em que avance, o trabalho de tradução vá construindo os topoi adequados: a) à zona de contato e à situação de tradução da língua na qual a argumentação é conduzida, uma vez que os saberes e as práticas presentes em uma determinada zona de contato cosmopolita, diante do multiculturalismo que lhe é peculiar, dificilmente têm uma mesma linguagem; b) aos silêncios, ou seja, aos ritmos diferentes com que cada saber ou prática articula as palavras com os silêncios e com os diferentes significados que cada cultura atribui ao silêncio.

Sem dúvida, a proposta de tradução de Boaventura de Sousa Santos (2002) pode ser considerada um processo de mediação da informação, incluindo o olhar do leitor e do tradutor, que no processo de tradução coloca-se, faz-se presente e por isso também é traduzido. Traduzir não significa transformar uma linguagem em outra, mas descobrir caminhos que ultrapassem as divergências de linguagens e comunicar, de modo singular, aquilo que não pertence à linguagem que formaliza, mas de quem se utiliza dela. Dessa forma, o procedimento de tradução contribui para que a comunicação existente entre profissionais de saúde e pacientes possa ser melhor compreendida e promova o letramento informacional dos indivíduos. O autor propõe o diálogo entre saberes como possibilidade de novas aprendizagens, por isso acredita-se, que a elaboração de bulas de medicamentos, envolvendo os profissionais da área e pacientes, possa promover o empoderamento dos indivíduos carentes de informações que lhes proporcionem melhores condições de saúde. Isso contribui para o avanço dos estudos sobre letramento informacional da área de Ciência da Informação, tendo como particularidade o letramento da área de saúde, bem como com as políticas públicas de proteção social voltadas para a educação e a saúde.

\section{LETRAMENTO INFORMACIONAL}

O letramento informacional é um conceito que tem produzido estudos em diversas instituições ligadas à pesquisa em todo $\mathrm{o}$ mundo, principalmente nas áreas de Biblioteconomia e Ciência da Informação. De acordo com a Association of College and

6 Os topoi ou loci são "lugares comuns", pontos de vista amplamente aceitos, de conteúdo muito aberto, inacabado ou flexível, e facilmente adaptável a diferentes contextos de argumentação. 
Research Library (2000, p.13), "refere-se a um conjunto de habilidades individuais que possibilitam ao sujeito reconhecer a informação necessária, bem como localizar, avaliar e utilizar eficazmente essa informação”. Para Gasque (2012, p. 32),

\begin{abstract}
"O letramento informacional tem como finalidade a adaptação e a socialização dos indivíduos na sociedade da aprendizagem. Isso ocorre quando o sujeito desenvolve as capacidades de: determinar a extensão das informações necessárias; acessar a informação de forma efetiva e eficientemente; avaliar criticamente a informação e as suas fontes; incorporar a nova informação ao conhecimento prévio; usar a informação de forma para atingir objetivos específicos; compreender os aspectos econômico, legal e social do uso da informação, bem como acessá-la e usála ética e legalmente".
\end{abstract}

$\mathrm{Na}$ sociedade da informação e do conhecimento, marcada pelo crescimento exponencial das informações, tais habilidades passaram a ser essenciais. A ideia de que "saber é poder", sintetiza a importância da informação e do conhecimento no contexto atual para o desenvolvimento da cidadania plena dos indivíduos e inclusão social. O relatório final do Presidential Committee on Infomation Literacy da American Library Association (ALA), destaca que "as pessoas competentes em informação são aquelas que aprenderam a aprender. Elas sabem como aprender, pois sabem como o conhecimento é organizado, como encontram a informação e como usá-la de modo que outras pessoas aprendam a partir dela" (AMERICAN LIBRARY ASSOCIATION, 1989).

Como tópico de pesquisa, o letramento informacional surgiu nos Estados Unidos na década de 70 sob a expressão Information Literacy, em um relatório elaborado pelo bibliotecário Paul Zurkowski, no qual ele sugeria ao governo norte-americano a promoção do desenvolvimento de habilidades informacionais junto à população, permitindo o uso das fontes eletrônicas que começavam a serem produzidas na época. Em sua opinião, isso possibilitaria a resolução de problemas no ambiente de trabalho, bem como a garantia de um mercado para indústrias da informação (CAMPELLO, 2009).

No Brasil, os estudos sobre o tema apareceram na primeira década do século XXI. Segundo Dudziak (2003), começou a ser estudado por bibliotecários que visavam desenvolver atividades voltadas para a educação de usuários das bibliotecas (atividade direcionada à capacitação para o uso dos sistemas de bibliotecas). Por se tratar de uma temática relativamente jovem, não há consenso entre os pesquisadores sobre a tradução exata para a expressão information literacy. Para a autora, 
[...] literacy é um conceito dinâmico e complexo. De acordo com o dicionário Houaiss (1982), a tradução corresponde "à capacidade de ler e escrever; alfabetização, instrução." Mas a simples tradução para alfabetização corresponderia a redução do conceito (nem todos os grupos sociais se utilizam do alfabeto) desvirtuando sua abrangência e propósito do contexto atual (DUDZIAK, 2001, p. 55).

De acordo com Campello (2003), o primeiro estudo brasileiro em que aparece a tradução da expressão "information literacy" é de autoria de Caregnato (2000), propondo a adoção do termo "alfabetização informacional". Cunha \& Cavalcanti (2008, p. 10) apresentam as seguintes variações terminológicas para a expressão: alfabetização informacional, educação para informação, fluência informacional, competência informacional e literácia informacional. $\mathrm{Na}$ literatura consultada, também foram identificadas outras traduções como competência informacional, competência em informação, info-competências (HATSBACH; OLINTO, 2008; ORELO; VITORINO, 2012). No livro "Overview of Information Literacy Resources Worldwide" a expressão information literacy (que possui várias acepções na literatura nacional e internacional), foi primeiramente traduzida na língua portuguesa (Brasil) como competência em informação (HORTON, 2013).

Neste artigo, optou-se por utilizar a expressão "letramento informacional", pelo fato de ser a expressão utilizada pelos autores, aqui citados, em seus trabalhos sobre o tema em questão.

Segundo Duziak (2003), o letramento informacional tem apresentado diferentes concepções, de acordo com a ênfase e o contex to em que se insere:

- ênfase na tecnologia da informação (concepção da informação) - nessa abordagem o letramento informacional está voltado para os sistemas de informação, onde a aprendizagem ocorre de forma mecânica e se limita à aquisição de habilidades e conhecimentos instrumentais. Predominou nas décadas de 70 e 80 com estudos de Zurkowski (1974) $)^{7}$, Taylor $(1979)^{8}$ e Garfield (1979) ${ }^{9}$;

- ênfase nos processos cognitivos (concepção cognitiva) - nessa abordagem o letramento informacional é compreendido como processo de busca de informação para a aquisição do conhecimento. Emergiu nos meados de 80 com os estudos de Breivik $(1985)^{10}$ e Kuhlthau (1987) ${ }^{11}$;

- ênfase no aprendizado (concepção da inteligência) - nessa abordagem, começou-se a enfatizar a aprendizagem, considerando a dimensão social e ecológica do indivíduo.

7 ZURKOWSKI, P. G. Information services environment relationships and priorities. Washington, D.C.:

National Commission on Libraries, 1974.

8 TAYLOR, R. S. Reminiscing about the future. Library Journal, New York, v. 104, p. 1895-1901, Sept. 1979.

9 GARFIELD, E. An information society? Journal of Information Science, Cambridge, v.1, p. 210, 2001.

10 BREIVIK, P. S. Putting libraries back in the information society. American Libraries, Chicago, v. 16, n. 10, p. $723,1985$.

11 KUHLTHAU, C. C. Inside the search process: information seeking from the user's perspective. Journal of

the American Society for Information Science, Washington, DC, v. 42, n. 5, p. 361-71, 1991. 
Bruce (1997) $)^{12}$ está entre os pesquisadores que a representa.

De acordo com Geraldi (2014), se em cada campo do conhecimento denominar-se o processo de "letramento", haverá tantos letramentos quantas forem as infinitas possibilidades de especialização das diferentes atividades humanas. Neste sentido, o adjetivo "diferente" associado ao letramento, mostra a real complexidade dos usos sociais da linguagem que nos torna diferentemente letrados ou iletrados ao mesmo tempo, de acordo com os diferentes campos de atividade.

Para mapear "diferentes" usos do letramento, Cosson (2015) propôs ler o termo em três concepções básicas seguindo o seu registro morfológico:

- primeira concepção: letramento no singular - essa associação retira do letramento o ideal de erudição letrada (parentesco até o século XIX) e o conduz à habilidade de ler e escrever. É o letramento básico e envolve a escolarização em massa das crianças e as dificuldades de inserção social, que sua ausência causa aos adultos no mundo do trabalho e na vida cotidiana. O uso mais comum do letramento no singular é a escrita, fazendo do conceito uma questão basicamente escolar, ou "quando se busca fazer uma leitura crítica do uso da escrita em uma determinada comunidade ou grupo social tornando o conceito mais localizado" (BARTON; HAMILTON; IVANIC, 2000) ${ }^{13}$;

- segunda concepção: letramento no plural - desloca-se a ênfase da habilidade de ler e escrever para a capacidade de se comunicar, de fazer uso dos instrumentos de representação da linguagem, reconhecendo-se o impacto das novas tecnologias nas relações sociais e culturais contemporâneas. Assim como as letras, os números também passam a ser essenciais, levando ao letramento matemático, quantitativo, digital tecnológico ou hipertextual (ESHET, 2004 ${ }^{14}$; GASQUE, 20105; PINHEIRO; ARAÚJO, $\left.2012^{16}\right)$;

- terceira concepção - O conceito pluralizado de múltiplos letramentos parece se particularizar pelo conhecimento ou área que servirá de adjetivo para focar em uma competência ou perspectiva crítica relativa a um campo do conhecimento. Para compreender o letramento adjetivado, um bom exemplo talvez seja o letramento em saúde (que abarca o conhecimento dos comportamentos saudáveis e outros aspectos referentes à promoção da saúde) (CHINN, 2011 ${ }^{17}$; KERKA, 2003 ${ }^{18}$ ), que será visto a seguir, por estar relacionado aos estudos da pesquisa em questão.

12 BRUCE, C. S. Seven faces of information literacy. Adelaide : Aslib, 1997

13 BARTON, D.; HAMILTON, M.; IVANIC, R. Situated literacies: reading and writing in context. Routledge: London, 2000.

14ESHET, Y. Digital literacy: a conceptual framework for survival skills in the digital era. Journal of

Educational Multimedia and Hypermedia, Norfolk, v. 13, n.1, p. 93-106, 2004.

15 GASQUE, K. C. G. D. Arcabouço conceitual do letramento informacional. Ciência da Informação, Brasília, v.39 n. 3, p.83-92, set./dez., 2010.

16 PINHEIRO, R. C.; ARAÚJO, J. Letramento hipertextual: por uma análise e redefinição do conceito. Revista

Brasileira de Linguística Aplicada, Belo Horizonte, v. 12, n. 4, p. 811-834, 2012.

17 CHINN, D. Critical health literacy: a review and critical analysis. Social Science \& Medicine, Oxford, n. 73, p. 60-67, 2011.

18 KERKA, S. Health literacy beyond basic skills. In: HULL, Glynda A. et al. Multiple literacies: a compilation for adult educators. Columbus, OH: Center on Education and Training for Employment, College of Education, The Ohio State University, 2003.

Comun. \& Inf., Goiânia, GO, v. 21, n. 3, p. 56-74, out./dez. 2018. 


\section{LETRAMENTO INFORMACIONAL EM SAÚDE}

O letramento informacional em saúde é essencial, tendo em vista que a qualidade de vida, os cuidados com a saúde e serviços relacionados são considerados direitos humanos universais. Isso faz com que todos os cidadãos tenham legalmente o direito ao acesso às informações relevantes à sua saúde e a saúde de seus familiares e comunidades (DUDZIAK, 2008). É também denominada "alfabetização para a saúde" ou "letramento em saúde" do inglês health literacy. Dowse e Ehlers (2005, p. 64) afirmam que:

Letramento em saúde é a capacidade que o indivíduo possui de obter, processar e compreender informações básicas sobre saúde e serviços necessários para decisões adequadas de saúde. Pessoas com baixo letramento em saúde apresentam os piores estados de saúde, menores conhecimentos sobre a doença e tratamento, aumento das internações, maiores custos de saúde e baixa adesão ao tratamento.

Freedbody e Luke (1990) estabelecem diferentes níveis para se obter letramento informacional que proporcione o acesso qualificado à informação em saúde:

- nível 1 - corresponde à alfabetização voltada à comunicação da informação sobre quais os agentes causadores de riscos à saúde e como utilizar o sistema de saúde. Para tal, faz-se necessária a produção de folhetos informativos com linguagem acessível a serem distribuídos entre os diversos atores sociais;

- nível 2 - equivale à alfabetização para a saúde interativa, onde se procura desenvolver a motivação e confiança do indivíduo, cuja finalidade é prepará-lo para atuar com o uso adequado da informação recebida;

- nível 3 - refere-se ao desenvolvimento da saúde em bases críticas, quando o indivíduo torna-se capaz de adotar atitudes, contribuir e influir no coletivo para análise e sustentação de ações sociais e políticas, de maneira que essa mudança comportamental se expanda socialmente.

Em 1999, a American Medical Association utilizou o termo functional health literacy - letramento funcional em saúde - LFS, que implica na prática (operacionalização) do próprio conceito de letramento. O LFS captura como as pessoas usam o letramento em saúde, não apenas como pacientes, mas também como membros de uma família, como trabalhadores, cidadãos (INSTITUTE OF MEDICINE, 2009).

Os conceitos de letramento funcional em saúde mais citados na literatura são os da World Health Organization (WHO), da American Medical Association (AMA) e Institute of Medicine (IOM) a seguir. 
Quadro 1 - Definições de letramento funcional em saúde

\begin{tabular}{l|l}
\hline $\begin{array}{l}\text { World Health Organization } \\
\text { WHO (1998, p. 10) }\end{array}$ & $\begin{array}{l}\text { "Competências cognitivas e sociais que determinam a motivação e } \\
\text { a capacidade dos indivíduos para obter acesso, compreender e } \\
\text { utilizar informação em meios que promovem e mantém uma boa } \\
\text { saúde." }\end{array}$ \\
\hline $\begin{array}{l}\text { American Medical Association } \\
\text { ad hoc Committee on Health }\end{array}$ & $\begin{array}{l}\text { Literacy - AMA, "uma constelação de habilidades, incluindo a capacidade de } \\
\text { realizar leitura básica e as tarefas necessárias para a função } \\
\text { numérica no ambiente de saúde. Os pacientes com o letramento } \\
\text { adequado em saúde podem ler, entender e agir sobre a informação } \\
\text { de saúde" [...] }\end{array}$ \\
\hline $\begin{array}{l}\text { Institute of Medicine - IOM } \\
\text { (2004, p. 32) }\end{array}$ & $\begin{array}{l}\text { "O grau pelo qual os indivíduos têm a capacidade para obter, } \\
\text { processar e entender informações básicas de saúde e serviços } \\
\text { necessários para a tomada de decisões adequadas em saúde." }\end{array}$ \\
\hline
\end{tabular}

Fonte: Elaborado pelas autoras do artigo, [2018].

Em relação a essas definiçõos conceituais de LFS, nota-se que esse é um termo em construção. A WHO (1998) faz menção às competências cognitivas e sociais, o LFS é visto como um resultado de ações de educação e promoção da saúde, com benefícios individuais e sociais. A definição da AMA (1999) mostra o constructo circunscrito ao contexto médico, no qual o vocábulo "paciente" indica uma posição determinada do indivíduo em um contexto de saúde bastante específico, não situando o LFS em uma ambiência mais ampla de saúde. A definição do IOM (2004) faz a alusão à "tomada de decisões adequadas em saúde", levando em consideração tanto os fatores individuais quanto os sociais, que por sua vez, influenciam na interação entre os usuários, os profissionais e o sistema de saúde (PASSAMAI et al., 2012).

Um esquema proposto por Sorensen et al. (2012) combina as qualidades do modelo conceitual do LFS de Paasche-Orlow e Wolf (2007) e de um modelo lógico, que mostra tanto os fatores que causam impacto como as vias que ligam o fenômeno do LFS aos resultados na saúde. O processo requer quatro tipos de competências: 1) Acesso - habilidade de procurar, encontrar e obter informações em saúde; 2) Compreensão - habilidade para compreender as informações que são acessadas; 3) Avaliação - habilidade para interpretar, filtrar, julgar e avaliar as informações em saúde acessadas; 4) Aplicação - diz respeito à habilidade para comunicar e usar as informações na tomada de decisão na manutenção e melhora da saúde. $\mathrm{Na}$ perspectiva desse modelo integrado, o processo é contínuo, independentemente de a pessoa estar doente, em risco de adoecer, participando de algum sistema de prevenção e promoção da saúde em sua comunidade, no local de trabalho, no sistema educacional e outros. 
De acordo com o IOM (2004), o sistema de saúde, o sistema educacional, junto à cultura e à sociedade, são setores que corroboram para melhorar o letramento em saúde, que existe a partir da interação do indivíduo nesse cenário. É um bem social em constante construção, devendo ser visto como "uma questão social, com implicações biomédicas" e não ao contrário.

Com base no exposto acima, vemos que a interação entre o sistema de saúde, o sistema educacional, a cultura e a sociedade refletem na prática o princípio da incompletude de todos os saberes, explicitado por Boaventura de Sousa Santos (2002). Ainda mostram a necessidade/possibilidade de diálogo e debate epistemológico entre essas diferentes formas de conhecimento para o letramento informacional em saúde dos indivíduos. São as perguntas sem respostas, as dúvidas, a ignorância, as fronteiras que impulsionam o diálogo entre saberes, entre sujeitos, produzindo teias sociais e políticas. Através da ecologia dos saberes se movimentam diálogos que remetem os sujeitos ao encontro, à comunicação, ao intercâmbio de informações. Nessa perspectiva, todos os saberes e todos os sujeitos têm a contribuir e a aprender, conforme teoriza Santos (2002).

\section{UMA EXPERIÊNCIA BEM SUCEDIDA}

No Brasil, ao longo das últimas décadas, mais precisamente na segunda metade do século $\mathrm{XX}$, a bula de medicamentos passou a ser o principal material informativo fornecido aos pacientes na aquisição desses produtos da indústria farmacêutica (CALDEIRA; NEVES; PERINI, 2008).

De acordo com Korolkovas, França e Cunha (2015), apesar de todo o esforço da Agência Nacional de Vigilância Sanitária (Anvisa) para a normatização dos modelos das bulas de medicamentos e da exigência para que os laboratórios a sigam, esse tipo de texto ainda se apresenta problemático e de difícil entendimento para o cidadão comum. Inerentemente complexa, fica a comunicação entre pacientes e profissionais, os quais querem se comunicar com clareza, mas tendem a usar terminologia técnica que lhes é familiar e muitas vezes, não conseguem termos equivalentes disponíveis na linguagem comum para o entendimento do público leigo.

Os pacientes com baixo letramento são mais limitados e necessitam mais ainda de ajuda para compreender e se beneficiarem das informações, visando à melhoria na saúde. Informações não compreendidas podem gerar barreiras aos pacientes, que refletem e talvez 
expliquem, entre outros, as baixas adesões aos tratamentos e pouco acesso aos serviços de prevenção e promoção da saúde (DOWSE; ELHERS, 2005).

O projeto para a criação de bulas mais compreensíveis, em linguagem mais simples, mais didática do que as dispostas no mercado aos pacientes, foi uma iniciativa da equipe de médicos e farmacêuticos do Hospital Universitário de Brasília (HUB), hospital público ligado à Universidade de Brasília (UnB). Iniciativa essa, criada a partir da vasta experiência desses profissionais em atenção farmacêutica de atendimento a pacientes de baixa renda e baixíssima escolaridade no HUB, abraçada por pacientes, alunos e demais profissionais da área de saúde da instituição.

De acordo com os coordenadores do projeto, ${ }^{19}$ a ideia de criar bulas mais fáceis de ler visa aumentar o conhecimento dos pacientes sobre saúde e nasceu após a constatação de que havia baixa adesão aos tratamentos, devido à incompreensão, por parte dos pacientes, às recomendações dos especialistas. Um dos motivos apontados por eles foi o não entendimento sobre os aspectos relacionados à prevenção e ao tratamento da doença. Outra causa é a falta de comunicação entre o profissional e o paciente, além de bulas indecifráveis e o baixo poder aquisitivo para seguir dietas recomendadas ou fazer exercícios.

Os membros da equipe do ambulatório de cardiologia do HUB/UnB constataram que seus pacientes não entendiam as informações contidas nas bulas tradicionais e que isso comprometia a adesão aos tratamentos propostos pelos especialistas e o uso correto dos medicamentos. Sendo assim, trouxeram para a cena social esses pacientes, colocando-os como atores centrais do processo de apropriação das informações contidas nas bulas, reconhecendo as suas limitações sociocognitivas e buscando alternativas para superá-las.

Verificou-se que no projeto de tradução, os pacientes passaram ao mesmo tempo a ser autores e coautores das bulas, tradutores e traduzidos. Participaram do processo de confecção e avaliação das mesmas (entendimento de vocabulário e imagens). As suas visões de mundo de leitores se introduziram no lugar do autor, suas percepções, releitura das informações dispostas nas bulas foram consideradas para se chegar a uma linguagem, que eles (pacientes) considerassem compreensível. Depois de elaboradas, as bulas traduzidas foram revisadas pelos próprios alunos do curso de pós-graduação em farmácia; pelos preceptores do ambulatório; discutidas em reuniões interdisciplinares do ambulatório; revisadas pelos pacientes, seguindo o ciclo até que se achasse a bula adequada.

O projeto de tradução das bulas de medicamentos da UnB, desenvolvido no período

19 Informações obtidas por meio de entrevista cedida em setembro/2017.

Comun. \& Inf., Goiânia, GO, v. 21, n. 3, p. 56-74, out./dez. 2018. 
de 2009 a 2011, foi visto como uma contra narrativa à formalização das práticas que envolvem a confecção das bulas para pacientes no Brasil, nas quais o paciente, principal leitor da bula, fica em uma posição passiva, apenas recebendo as informações e não contribuindo com a comunicação, que deveria acontecer entre produtores e consumidores. De acordo com Cintra (2012), isso torna a comunicação entre autor e leitor assimétrica, pois somente o autor da bula, no caso, o grupo de farmacêuticos do laboratório que comercializa o medicamento ou um redator contratado tem algo a comunicar.

Percebeu-se na análise das etapas do trabalho de tradução das bulas de medicamentos para cardiologia no HUB/UnB, que para a promoção do letramento informacional em saúde dos pacientes, houve a necessidade de se integrar múltiplos saberes, (médicos, farmacêuticos, agentes de saúde, assistentes sociais, pedagogos), que serviram de base para o desenvolvimento de habilidades, visando propiciar aos pacientes autonomia para tomarem decisões assertivas sobre a saúde. Procurou-se identificar as preocupações isomórficas entre essas diferentes culturas e as diferentes respostas que lhes foram dadas, com vistas a se criar inteligibilidade recíproca entre as experiências de mundo dos pacientes e dos profissionais da saúde, para a composição dos textos das bulas traduzidas. Nesse viés, que se vislumbrou como os fundamentos teóricos do procedimento de tradução proposto por Boaventura de Sousa Santos, complementaram-se perfeitamente. Isso porque o autor, em seus estudos, destaca que "o trabalho de tradução incide tanto sobre os saberes, quanto sobre as práticas e os seus agentes" (Santos, 2002, p. 31).

Apesar de os coordenadores do projeto de tradução das bulas de medicamentos para cardiologia do HUB/UnB informarem que não têm conhecimento direto da teoria de Boaventura, os reflexos de seus pensamentos podem ser sentidos no objetivo da equipe sobre o porquê do trabalho e sobre como realizá-lo. Isso indica, que mesmo sem terem se debruçado sobre o pensamento do autor, a difusão e o entrelaçamento de suas ideias ao senso comum do meio científico brasileiro podem ser percebidas no trabalho de tradução desenvolvido no $\mathrm{HUB} / \mathrm{UnB}$.

Portanto, a contribuição de Boaventura para a promoção do letramento em saúde dos pacientes é a proposta do diálogo entre diferentes culturas e saberes - no caso em questão, entre pacientes e profissionais de saúde - na busca por respostas que não se encontram dentro dos limites de seus saberes/práticas de origem, visando criar inteligibilidades recíprocas entre os envolvidos. 


\section{MARCO EMPÍRICO}

A bula traduzida ${ }^{20}$ no ambulatório de cardiologia do HUB/UnB foi distribuída aleatoriamente para leitura prévia a 35 pacientes, com idade entre 18 a 88 anos e estudos que vão desde o quinto ano do Ensino Fundamental, até o curso de pós-graduação em nível de especialização. Após a leitura, foram feitas aos entrevistados perguntas sobre as informações dispostas na bula relativas aos tópicos: Para que serve o medicamento? Qual a dose correta desse remédio? Situações em que não deve ser utilizado? E reações indesejáveis? Tais tópicos foram selecionados, pois segundo Dickinson e Raynor (2003), referem-se às informações que os pacientes priorizam ao consultar uma bula de medicamentos. Os 35 pacientes entrevistados responderam assertivamente todos os itens perguntados sobre o medicamento. As habilidades dos entrevistados se limitaram à leitura de informações apresentadas de forma explícita, sem a contribuição de noções científicas para apoiarem a sua compreensão da realidade. Isso faz com que na prática, possa-se inferir, que as informações contidas na bula traduzida consultada criam inteligibilidades recíprocas entre os diversos leitores que as consultam, com diferentes graus de instrução e diversidade sociocognitiva, contribuindo para a promoção do letramento informacional em saúde dos pacientes e, por conseguinte, resultando no uso assertivo do medicamento.

A bula traduzida foi considerada pelos entrevistados como um documento que contém informações: claras; explicativas; de fácil entendimento; ela permite ao leitor ler e entender o texto. Os entrevistados também puderam opinar sobre a importância da participação dos pacientes num estudo-piloto, para a revisão das bulas elaboradas pelos laboratórios farmacêuticos e aprovadas pela Anvisa, antes da comercialização dos medicamentos. Eles relataram que os pacientes, como consumidores finais do produto, poderão repassar aos laboratórios farmacêuticos, as possíveis dúvidas sobre as informações dispostas sobre o uso do medicamento e dessa forma, pode-se alterar o texto por meio de uma linguagem mais didática. Outros citaram que quando não entendem uma palavra disposta no texto da bula, recorrem ao dicionário, onde localizam termos sinônimos que proporcionam maior clareza para a expressão citada. Acreditam que dessa forma, poderão contribuir, sugerindo como melhor se entende o que está descrito e que provavelmente também atenderá a outros pacientes.

20 A bula selecionada para a entrevista com os pacientes foi a do medicamento AAS (Ácido Acetil Salicílico), pelo fato de tratar-se de um medicamento muito conhecido em todo o mundo. Inicialmente usado como analgésico, anti-inflamatório e antitérmico, a droga passou a ser utilizada no auxílio do tratamento de doenças do coração. Em 1906, o comprimido já era conhecido como "droga maravilha" e, ainda hoje, é o remédio mais consumido no mundo - só nos Estados Unidos, são cerca de 80 milhões de AAS por dia (MEDEIROS, 2006). 
Retomando os constructos teóricos da teoria de tradução de Boaventura de Sousa Santos e suas contribuições para a área de letramento informacional na Ciência da Informação, pode-se inferir que a necessidade da participação dos sujeitos sociais nos processos de tradução das informações, proposta pelo autor, é fundamental. Pode-se comprovar tal fato pelo sucesso de entendimento dos pacientes do ambulatório de cardiologia do HUB/UnB e, ainda permitiu a ressignificação da informação dos textos das bulas, contextualizando-a em sua vivência, fazendo com que a informação que circula entre emissor e receptor possa ser mais bem compreendida por dispor de um repertório comum de signos, evitando-se distorções.

A Ciência da Informação possui como um dos maiores preceitos, a convicção que a informação deve ser entendida e apropriada pelos usuários. Sem entendimento não há informação, somente pode-se chamar de informação algo que se compreende, isto é, "se existe por parte do sujeito cognoscente, consenso em relação ao seu significado, caso contrário não é informação. Assim, o sujeito cognoscente ressignifica a informação, uma vez que infere síntese e contexto a ela" (FADEL et. al., 2010, p. 15).

\section{CONSIDERAÇÕES FINAIS}

Os preceitos de letramento informacional na Ciência da Informação se referem a um conjunto de habilidades individuais, que possibilitam aos atores sociais reconhecerem as informações necessárias, localizá-las, avaliá-las e utilizá-las eficazmente. Certamente, esse é também o objetivo de outras áreas do conhecimento científico: disseminar informações e proporcionar a sua apropriação. No caso específico desta pesquisa, verificou-se, que estudos desenvolvidos na área da saúde também demonstram o interesse de pesquisadores médicos e farmacêuticos pela temática. O letramento se entrelaça e se direciona à saúde, uma vez que a qualidade de vida e os seus cuidados são considerados direitos humanos universais, fazendo com que todos os cidadãos tenham legalmente o direito ao acesso às informações relevantes à sua saúde.

O procedimento de tradução, proposto por Boaventura de Sousa Santos (2002), consiste no trabalho de interpretação entre duas ou mais culturas, objetivando identificar as preocupações isomórficas entre elas e as diferentes respostas que lhes são dadas, com vistas a se criar inteligibilidade recíproca entre as experiências do mundo. Acredita-se, que conhecer a visão de mundo do outro, partilhá-lo com quem não partilha o nosso saber ou a nossa experiência, conforme teoriza Santos (2002), são condições que favorecem a tradução entre 
saberes e contribuem para o letramento informacional em saúde dos pacientes, que buscam por melhores condições de saúde. Isso acarreta maior adesão aos tratamentos propostos pelos especialistas, redução de internações e menores gastos com a saúde da população.

$\mathrm{Na}$ área da Ciência da Informação, os constructos teóricos da tradução reforçam a importância da participação dos usuários nos processos da disseminação da informação, entre diferentes formas de saberes e sujeitos, no âmbito da construção do conhecimento e das relações entre mediação e apropriação da informação, com vistas a promoção da competência informacional e ao empoderamento dos cidadãos para que eles exerçam a cidadania e o autoconhecimento e convivam melhor na sociedade. Contribuem ainda para os novos estudos de usuários da informação, que se desenvolvem a partir do conceito de "práticas informacionais". Esses estudos constituem-se num movimento constante de capturar as disposições sociais, coletivas e também as elaborações e perspectivas individuais de como se relacionar com a informação, englobando as noções de interação e de contexto junto à ação dos sujeitos que fazem uso, produzem e se apropriam de informação e de conhecimento (ARAÚJO, 2017). Nesse viés, os aportes teóricos do procedimento de tradução proposto por Boaventura podem permitir a compreensão de modo mais vertical ou intrínseco dos atores sociais pesquisados.

Segundo Gomes e Varela (2016, p.19), “o saber laboral e o saber científico necessitam do substrato informacional especializado, sendo que, no caso do primeiro, em um nível de informações de caráter individual e familiar de cada paciente". Juntos, esses saberes corroboram para a formação de um conjunto de informações que podem assegurar o projeto terapêutico. Para as autoras, essa dimensão acerca da informação na área da saúde, sinaliza a importância da mediação da informação entre médicos e pacientes, podendo-se situar o profissional da informação, que também é consultado por ambos para identificar novas perspectivas de soluções, na busca de melhores condições de saúde. Nesse contexto, o procedimento de tradução proposto por Boaventura reafirma a necessidade e a importância do diálogo entre saberes como possibilidade de novas aprendizagens que certamente contribuirão para a promoção da saúde dos envolvidos.

\section{REFERÊNCIAS}

AMERICAN LIBRARY ASSOCIATION. Report of the Presidential Comittee on

Information Literacy: Final report. Washington, D.C, 1989. 
AMERICAN MEDICAL ASSOCIATION AD HOC COMMITTEE ON HEALTH LITERACY (AMA). Health literacy: report of the council on scientific affairs. JAMA, Chicago, v. 281, n.6, p.552-557, 1999.

ARAÚJO, C. A. Á. O que são práticas informacionais. Informação em Pauta, Fortaleza, v. 2, p. 218-236, out. 2017. Número especial.

\section{ASSOCIATION OF COLLEGE AND RESEARCH LIBRARY. Information literacy competency standarts for higher education. Chicago, 2000.}

BUCK, M. L. Providing patients with written medication information. Ann. Pharmacother, Cincinnati, OH, v. 32, p. 962-969, sep./1998.

CALDEIRA, T. R.; NEVES, E. R. Z.; PERINI, E. Evolução histórica das bulas de medicamentos no Brasil. Cadernos de Saúde Pública, Rio de Janeiro, v.24, n.4, p.737-743, 2008.

CAMPELLO, B. S. O movimento da competência informacional: uma perspectiva para o letramento informacional. Ciência da Informação, Brasília, v. 32, n. 3, p. 28-37, set./dez. 2003.

Letramento informacional: função educativa do bibliotecário na escola. Belo Horizonte: Autêntica, 2009.

CAREGNATO, S. E. O desenvolvimento de habilidade informacional: o papel das bibliotecas universitárias no contexto da informação digital em rede. Revista de Biblioteconomia \& Comunicação, Porto Alegre, v. 8, p. 47-55, 2000.

CINTRA, A. D. Bulas de medicamentos alemãs e brasileiras em contraste: alguns resultados da análise linguística. Pandeamonium, São Paulo, v.15, n.20, p.224-261, 2012.

COSSON, R. Letramento literário: uma localização necessária. Letras \& Letras, Uberlândia, v. 31, n. 3, jul./dez. 2015.

CUNHA, M. B.; CAVALCANTI, C. R. Dicionário de Biblioteconomia e Arquivologia. Brasília: Briquet de Lemos, 2008.

DICKINSON, D.; RAYNOR, D. K. What information do patients need about medicines? Ask the patients: they may want to know more than you think. BMJ, London, v. 327, n. 7419, p. $861,2003$.

DOWSE, R.; EHLERS, M. Medicine labels incorporating pictograms: do they influence understanding and adherence? Patient Education and Counseling, Limerick, v. 58, n.1, p.63-70, 2005.

DUDZIAK, E. A. Os faróis da sociedade da informação: uma análise crítica sobre a atuação da competência em informação no Brasil. Informação \& Sociedade: Estudos, João Pessoa, v. 18, n. 2, p. 41-53, maio/ago. 2008. 
A information literacy e o papel educacional das bibliotecas. 2001. $173 \mathrm{f}$.

Dissertação (Mestrado em Ciências da Comunicação) - Escola de Comunicações e Arte, Universidade de São Paulo, São Paulo, 2001.

Information literacy: princípios, filosofia e prática. Ciência da Informação, Brasília, v. 32, n. 1, jan./abr. 2003.

FADEL, B. et. al. Gestão, mediação e uso da informação. In: VALENTIM, M. [Org.].

Gestão, mediação e uso da informação. São Paulo: Acadêmica, 2010, p. 13-31.

FREEBODY, P.; LUKE, A. Literacies programs: debates and demands in cultural context. Prospect: An Australian Journal of Teaching, Sydney, n. 5, p. 7-16, 1990.

GAL, I.; PRIGAT, A. Why organizations continue to create patient information leaflets with readability and usability problems: an exploratory study. Health Education Research, Oxford, v. 20, p. 485-493, 2005.

GASQUE, K. C. G. D. Letramento informacional: pesquisa, reflexão e aprendizagem. Brasília: Faculdade de Ciência da Informação / Universidade de Brasília, 2012.

GERALDI, J. W. A produção dos diferentes letramentos / Production of different Literacies. Bakhtiniana, São Paulo, v. 9, n. 2, p. 25-34, ago./dez. 2014.

GOMES, H. F.; VARELA, A. V. Mediação da informação na área da medicina: possibilidades de interlocução entre os saberes científico, profissional e sociocultural. Perspectivas em Ciência da Informação, Belo Horizonte, v.21, n.1, p. 3-22, jan./mar. 2016.

HATSBACH, M. H. L.; OLINTO, G. Competência em informação: caminhos percorridos e novas trilhas. Revista Brasileira de Biblioteconomia e Documentação, São Paulo, v.4, n.1, p. 20-34, jan./jun. 2008. Nova série.

HORTON, F. W. [Org.]. Overview of information literacy resourcesworldwide. Paris: Unesco, 2013. Disponível em: <http://repositorio.minedu.gob.pe/bitstream/handle/123456789/2897/Overview\%20of\%20inf ormation $\% 20$ literacy $\% 20$ resources $\% 20$ worldwide.pdf?sequence $=1 \&$ isAllowed $=y>$ Acesso em 23 jan. 2018.

INSTITUTE OF MEDICINE (IOM). Health Literacy: a prescription to end confusion. Washington, DC: National Academies Press; 2004.

INSTITUTE OF MEDICINE (IOM). Measures of Health Literacy: workshop summary. Washington, DC: The National Academies Press, 2009.

KOROLKOVAS, A.; FRANÇA, F. F.; CUNHA, B. C. A. DTG, Dicionário Terapêutico Guanabara: edição 2014-2015. 21. ed. Rio de Janeiro: Guanabara Koogan, c2015.

LEITE, R. F., VENTURA, C. A. A. Direito à informação em saúde: acesso à informação sobre diagnóstico, exames, medicamentos, riscos e benefícios do tratamento. In: CONGRESSO BRASILEIRO DE BIBLIOTECONOMIA, DOCUMENTAÇÃO E CIÊNCIA DA INFORMAÇÃO, 24, Maceió, 2011. [Anais...], Maceió, 2011. 
MEDEIROS, C. Ácido Acetilsalicílico: o comprimido 1001 utilidades. Viva saúde online, 2006. Disponível em: <https://vivasaude.digisa.com.br/edicoes/22/artigo14912-1.asp/> Acesso em 23 jan. 2018.

ORELO, E. R. M.; VITORINO, E. V. Competência informacional: um olhar para a dimensão estética. Perspectivas em Ciência da Informação, Belo Horizonte, v. 17, n.4, p. 41-56, out./dez. 2012

PAASCHE-ORLOW, M. K.; WOLF, M. S. The causal pathways linking health literacy to health outcomes. American Journal of Health Behavior, Oak Ridge, v. 31, n. 1(suppl), p. S19-S26, 2007.

PASSAMAI, M. P. B. et al. Letramento funcional em saúde: reflexões e conceitos sobre seu impacto na interação entre usuários, profissionais e sistema de saúde. Interface -

Comunicação, Saúde, Educação, São Paulo, vol. 16, n. 41, p. 301-314, abr./jun. 2012.

SALDANHA, J. M. L. Da teoria geral do processo à teoria da tradução: um aporte da sociedade das ausências e das emergências. In: DIDIER JÚNIOR, F.; JORDÃO, E. F. (Orgs.). Teoria do processo: panorama doutrinário mundial. Salvador: JusPodivm, 2007. p. 389-428.

SANTOS, B. de S. Para uma sociologia das ausências e uma sociologia das emergências. 2002. Disponível em: 〈https://www.ces.uc.pt/bss/documentos/sociologia_das_ausencias.pdf > Acesso em 10 fev. 2018.

SORENSEN, K. et al. Health literacy and public health: a systematic review and integration of definitions and models. BMC Public Health, London, v.12, n. 80, p. 1-13, 2012.

WHO. WORLD HEALTH ORGANIZATION. Health promotion glossary. Geneva: WHO, 1998. 